\title{
Mario Paint: An Accessible Environment of Musical Creativity and Sound Exploration
}

\author{
Dr. Christopher Hopkins \\ Long Island University, Brookville, USA \\ Five Towns College, Dix Hills, USA
}

\begin{abstract}
Mario Paint, the 1992 Nintendo game for the Super NES, remains an accessible environment for musical creativity and sound exploration within its music mode. Although developed for a gaming system, the game's music mode is a streamlined tool built upon basic music theory and music composition. Through familiar video game sounds and icon and Western music notation, players are able to compose chiptune works and explore the nature of sound through an inviting interface. Similar music composition software upgrades the process of composition established in Mario Paint, allowing for digital distribution and dissemination. Mario Paint continues to inspire new projects in the areas of video games and scholastic studies. Mario Paint and its successors are very reasonable entry-level programs for chiptune composers and fledgling music students.
\end{abstract}

Keywords: music composition, Super NES, Nintendo, music theory, music production, sound chip

\section{Introduction}

For beginning and amateur musicians and composers, the music mode found in the 1992 Nintendo game Mario Paint offers an affordable access point for the development of skills in music theory and composition. The design of the interface and the decisions of sounds, features, and limitations show that Nintendo understands the intended audience and the creativity that results from such an optimized tool. To this day, aspiring music students and composers, especially those considering a career in the video game industry, can greatly benefit from working efficiently within the environment of Mario Paint, all from a video-game perspective.

Mario Paint is a video game published and released by Nintendo in North America for the Super NES in August of 1992. Although there are some game elements in Mario Paint, it was marketed as an art program. The overall user interface is designed around the $\mathrm{SNES}^{1}$ mouse input device that comes with the game. This aligns the game with computer software for art like Windows Paint and Adobe Photoshop. It is by no means as developed and detailed as those programs, but it offers a variety of activities for casual and serious users, including picture coloring, stamp creation, animations, and music composition (Mario Paint, n.d.).

Mario Paint is one of the first games to allow music composition on a video game console. One of the modes in the game is the music mode. This mode allows a user to play and compose music for the sound chip of the

\footnotetext{
Christopher Hopkins, Doctor, Long Island University and Five Towns College. Learn more about Dr. Christopher Hopkins at http://www.christopherjhopkins.com.

${ }^{1}$ It is the abbreviation of Super NES.
} 
Super NES. Earlier commercial audio software appeared on the Commodore Amiga; ${ }^{2}$ however, music composition on Mario Paint is more accessible and inviting. Before the convenience of mobile and portable Apps, Mario Paint was one of the easiest programs to use to write out notes and hear them quickly.

\section{Interface}

In an evaluation of its interface, Mario Paint resembles a condensed version of industry-standard music notation software such as Finale by MakeMusic and Sibelius by Avid. However, Mario Paint does not require the complexities of such software to promote musical creativity and sound exploration. The interface combines game-like elements with formal music iconography; these represent the essential features that work within the sound chip of the Super NES.

Figure 1 shows the interface found in the music mode of Mario Paint. Measure numbers appear above the staff. Lightly-colored bar lines represent the beats of each measure. Icons on the staff represent pitches in the same way as notes do in Western sheet music notation. The music mode avoids the complexity of multiple staves by placing all sound types on the same treble staff. The interface avoids the visual inaccuracy that would result from two icons residing at the same pitch on the same beat by disallowing it. Therefore, two sounds cannot be placed at the same pitch at the same time.

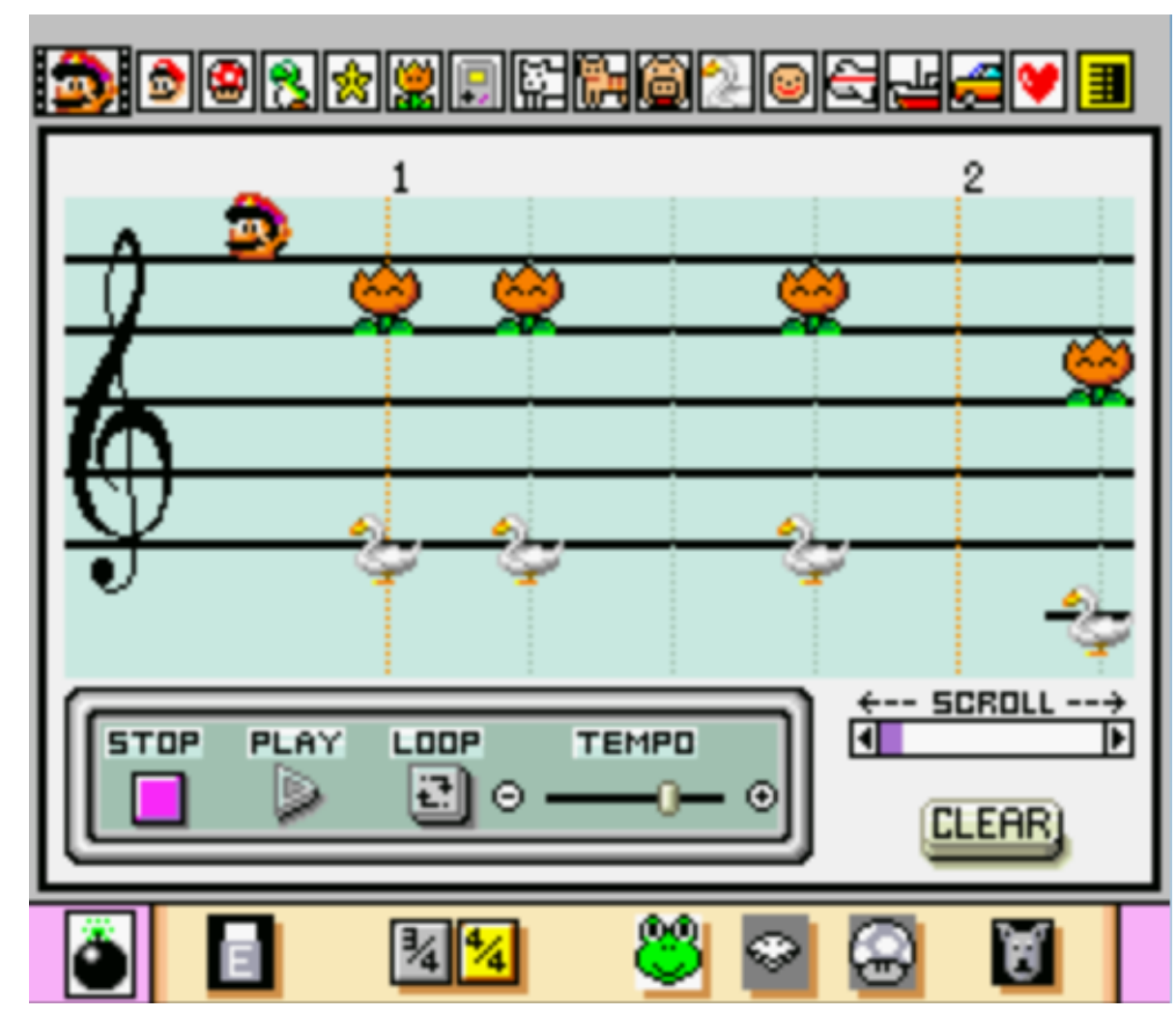

Figure 1. Interface from Mario Paint.

The top bar contains the sound selection and final bar line buttons. The large icon in the upper-left box represents the sound that is currently selected. The next 15 icons, while appearing enigmatic, represent the

\footnotetext{
${ }^{2}$ Ultimate Soundtracker.
} 
available sounds to add to the song. Table 1 identifies the icons with their associated sounds. The final bar line button is located in the upper-right corner. When selected, it allows the user to place a final bar line on any beat visible on-screen. This is useful for songs that do not require the maximum number of beats.

Table 1

Mario Paint Icons From Left to Right and Their Associated Timbres

\begin{tabular}{|l|l|}
\hline Icon & Timbre \\
\hline Mario & Wooden Xylophone \\
\hline Mushroom & Tom \\
\hline Yoshi & Ride Yoshi sound from Super Mario World \\
\hline Star & Light metallic percussion \\
\hline Flower & Trumpet \\
\hline Game Boy & Square Wave \\
\hline Dog & Arff \\
\hline Cat & Meow \\
\hline Pig & Snort \\
\hline Goose & Orchestra Hit \\
\hline Baby Face & Gurgle \\
\hline Jet & Piano/Acoustic Guitar \\
\hline Boat & Wood Block \\
\hline Car & Electric Organ \\
\hline Heart & Bass Guitar \\
\hline
\end{tabular}

At the time of Mario Paint's release, the MIDI ${ }^{3}$ format was in an early stage of development. MIDI is a standard that allows musical devices and computers to connect and communicate with one another. The development of the MIDI format may have influenced the presence of sound effects in Mario Paint. In both settings, sound effects are not ideal to be repitched, whereas instrument sounds work well within a musical arrangement at various pitches. For example, the animal sounds are a novelty that obscure their recognizability at different pitches. Mario Paint does not use MIDI data, but acknowledges emerging trends in MIDI by its selection of instrument sounds and animal noises.

Underneath the top bar is a five-lined treble staff which represents different pitches. This is in contrast to the piano-roll interface found in modern $\mathrm{DAWs}^{4}$ and the grid interface found in tracker software. The progression of time is based horizontally, just as the piano-roll interfaces of modern DAWs.

Below the staff are the playback controls. The buttons on the left side represent play, stop, and loop functions. When the loop button is selected, the song will seamlessly restart after the final measure. Looping is a common trait of early game music. There is a scrollbar in the center labeled "tempo" which allows the user to select the speed in which the song plays. On the right side, there is a bar labeled "scroll position" which shows the placement of the current part of the song within the whole song. Below the scrollbar is the clear button which creates an empty song.

The bottom bar in the interface houses miscellaneous editing and song buttons. The bomb icon quits the music mode and returns the user to the paint mode. The eraser icon allows the user to click on a note and remove

\footnotetext{
${ }^{3}$ It is the abbreviation of Musical Instrument Digital Interface.

${ }^{4}$ It is the abbreviation of Digital Audio Workstation.
} 
it from the staff. There is a time signature selector from which the user can choose between 3/4 and 4/4 meters. The time signature chosen affects the placement of the measure numbers and beat lines. The three icons of a frog, puppet, ${ }^{5}$ and Mario mushroom select one of three pre-recorded songs. The frog icon selects "Overworld Theme" from Super Mario Bros., the puppet icon selects “Twinkle, Twinkle Little Star”, and the mushroom icon selects an original song. The third song is used in a commercial for the Japanese version of Mario Paint (Japan commercials $4 \mathrm{U} 2,2009)$. The dog icon in the bottom-right corner is a standard undo feature, retracting the last user action. These actions include adding or removing a note, changing the tempo, or moving the final bar line.

\section{Features}

The music mode is but one of the various modes in Mario Paint. This does not detract from the music mode's feature selection encouraging musical exploration. The sounds of the Super NES sound chip are available for music composition along with the sound chip's limitations. Due to the interdependency of music with the game system, music composition on Mario Paint is most appropriate for chiptunes, the music made from vintage sound chips of the 1980s and 1990s. Below are the distinguishing features of Mario Paint.

(1) The available pitches are the white keys from B4 to G5 inclusive. ${ }^{6}$

(2) There are forty tempo settings ranging from 40 to 480 beats per minute. $^{7}$

(3) A song can have a maximum of 96 beats of music. When the $4 / 4$ time signature is selected, there are twenty-four measures of music. When the $3 / 4$ time signature is selected, there are thirty-two measures of music.

(4) There are three demo songs which use the various sounds in creative ways. They can be used as a template and are editable.

(5) Mario runs and jumps above the staff during playback in much the same way as a bouncing ball in a sing-along video.

\section{Limitations}

Music composition within Mario Paint's music mode is restricted by the Super NES' sound chip and design choices. These limitations are explained below (Trammell, 2010).

(1) The interface only considers $4 / 4$ and 3/4 time signatures. The choice affects the placement of measure numbers and beat lines; however, one can still compose in other meters without a visual representation of beats.

(2) The maximum song length is 96 beats. In 4/4 time, this is twenty-four measures. In 3/4 time, this is thirty-two measures.

(3) There is a maximum of three simultaneous sounds at a time.

(4) Only one sound may reside on a pitch at a time. There cannot be two sounds at the same pitch at the same time.

(5) The quarter note is the only note value available, although it does not function as such. Instead, each note plays a sound at a certain pitch until either the sound sample ends or another note of any sound or pitch interrupts. ${ }^{8}$

\footnotetext{
5 Mario Paint: Nintendo Player's Guide identifies the icon as a puppet, but it looks more like a serpent head.

6 C4 represents middle $\mathrm{C}$ on a keyboard.

7 Another way to understand it is as 10 to 120 measures of $4 / 4$ per minute. The duration of a song ranges from 12 seconds to 2 minutes and 24 seconds.

${ }^{8}$ This is best demonstrated with adjacent notes using the car icon as it is the longest audio sample available.
} 
(6) Despite the range of tempo, there are only forty preset tempo settings. While forty should be manageable, this limitation makes accurate transcription difficult.

(7) There are no dynamics. Every note plays at the same volume.

(8) There are no sharps or flats.

(9) The pitch range is limited to an octave and a minor 6th in the treble register. ${ }^{9}$

(10) The available pitches favor composition in the key of C major or A natural minor. These keys only work for songs that are completely diatonic.

(11) The game does not have a save feature. Such a feature would have added value to the game. In the early 1990s, the only reasonable method to save original content from Mario Paint was through videotape recording.

\section{Mario Paint as an Accessible and Capable Audio Environment}

Although Mario Paint is considered a game, its music mode should not be disregarded as inconsequential to music education. On the contrary, Mario Paint combines the best of the Western musical tradition with Nintendo's standard for gaming fun. Most players are familiar with the basics of Western music notation. The five lined-staff found in Mario Paint is intuitive for note input at the expense of additional control of musical data, available in tracker software. Mario Paint contains sounds from games and sound chips with which players would be familiar. For example, the Yoshi and Game Boy sounds are associated with Super Mario World and the Game Boy handheld gaming system, respectively. While a typical orchestral score displays a staff for each instrument, Mario Paint avoids the complexity by using kid-friendly icons to represent timbres all on the same staff.

The interface of Mario Paint favors the Super NES mouse as input. This was uncommon at the time for video game play. Without the mouse, the design of the interface would have been flawed and difficult to navigate for music. The mouse design relates to the mouse as used with computers. In the case of Mario Paint, the process of creating and editing within the various modes is no different than the workflow of a computer's various software programs.

Although Mario Paint lacks a save feature, any song can be recreated with the images of the notes on the treble staff. Therefore, any simple song with a melody, harmony, bass, and drums can be arranged in Mario Paint and any song written in Mario Paint can be arranged for standard instruments. This associative relationship is valuable to a video-game-music composer as one studies and applies music theory in acoustic and electronic sound settings. The 15 sounds available are adequate for lively musical arrangements. As one experiments with the sounds in a musical context, one may find insight into how memorable game soundtracks are conceived.

The game is appealing to young people as a popular game on a popular gaming console and being published and released by Nintendo, a prominent video game company in the industry then and now. Nintendo supported a growing community of gamers with gaming publications like Nintendo Power. Some of these issues encourage advanced art and music techniques in Mario Paint (Hackett, 2013). These documents use words and pictures to recreate familiar scenes and songs from TV and video games. ${ }^{10}$ Mario Paint: Nintendo Player's Guide, an

\footnotetext{
${ }^{9}$ Although visually represented by a treble clef, some sound samples are set at different octaves. For example, the sounds of the jet and heart icons are in a lower register than the other sounds.

${ }_{10}$ Some of the songs included are the Overworld Theme of Super Mario Bros., the Main Theme from Star Wars, and The Blue Danube.
} 
exclusive book dedicated to Mario Paint, contains an eleven-page section dedicated to music composition (Mario Paint: Nintendo Player's Guide). Based on the content of these documents, Nintendo valued the music mode, detailing topics of music theory and music composition, some being melody, harmony, rhythm, bass, styles, scales, and chords. ${ }^{11}$ The music mode of Mario Paint displays an integration of musical studies and accessibility, resulting in a user experience that builds skills in music theory and composition through experimentation and creative choice.

\section{Improvements to Mario Paint's Music Mode}

Since the release of Mario Paint, a few software programs have improved upon its established musical process while maintaining accessibility. The most significant improvements in these programs are saving songs, extending the length of songs, and playing more simultaneous sounds. Each program attempts to improve functionality while maintaining the accessibility that makes Mario Paint an enjoyable experience.

\section{Mario Sequencer (2002)}

Mario Sequencer is an early implementation of Mario Paint that strictly adheres to the musical features and limitations of the original game (eataninja, 2011). As a result, accidentals are not present, compositions may only have at most 96 beats, and the maximum simultaneous notes at a time are three. The interface resembles Mario Paint within the Windows operating system (see Figure 2). It rectifies glaring weaknesses of Mario Paint by the loading and saving of songs and the easy distribution of song files.

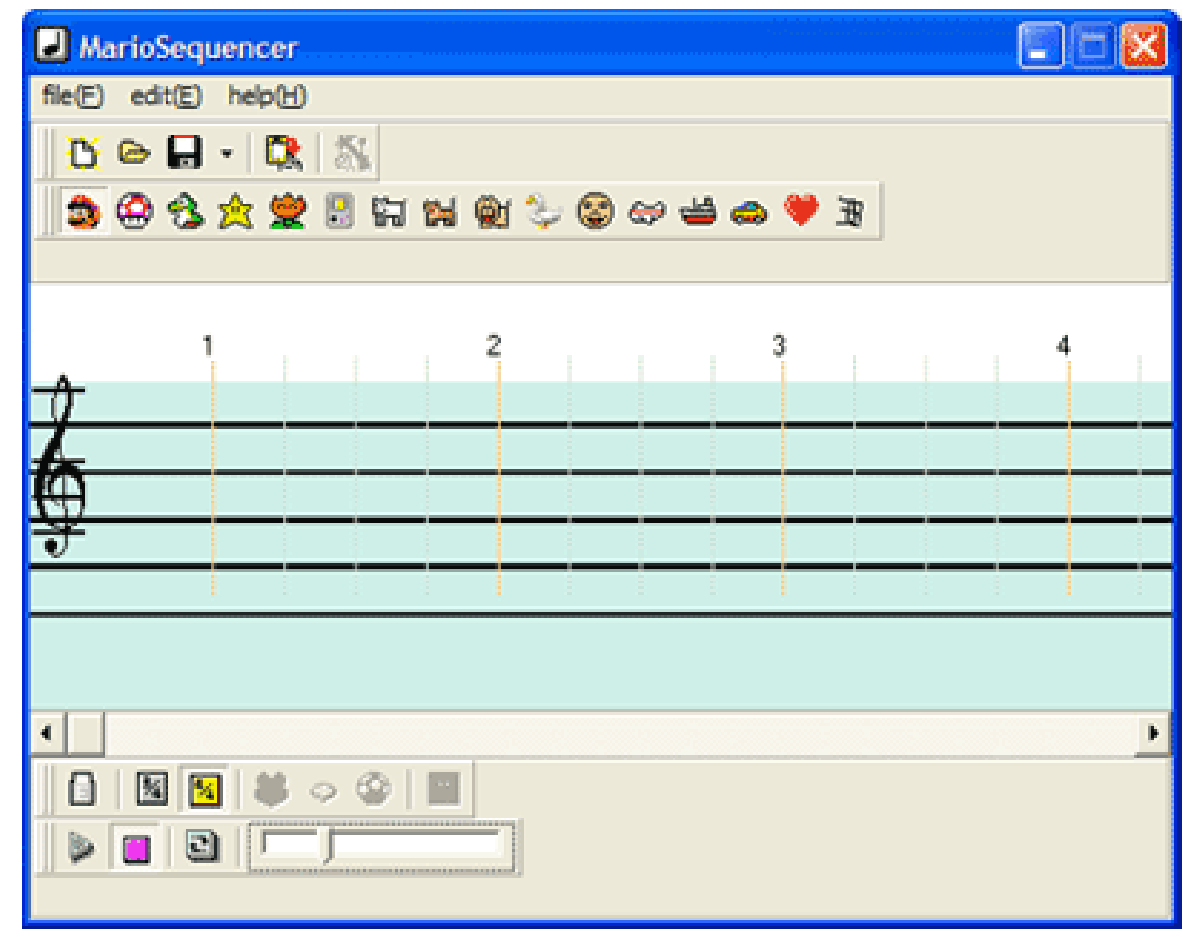

Figure 2. Interface from Mario Sequencer.

\footnotetext{
11 The guide contains a thorough explanation of diatonic triads, different rhythmic styles like a bossa-nova and reggae, and the C major scale.
} 


\section{Mario Paint Composer v2.0 (2007)}

Mario Paint Composer by Unfun Games is a popular music-composition program inspired by Mario Paint. It adds new features that remove most of the limitations of the original game while encouraging longer, more intricate songs. Some of these features are located in the tan areas of the interface as seen in Figure 3. Changes from Mario Paint and Mario Sequencer appear below.

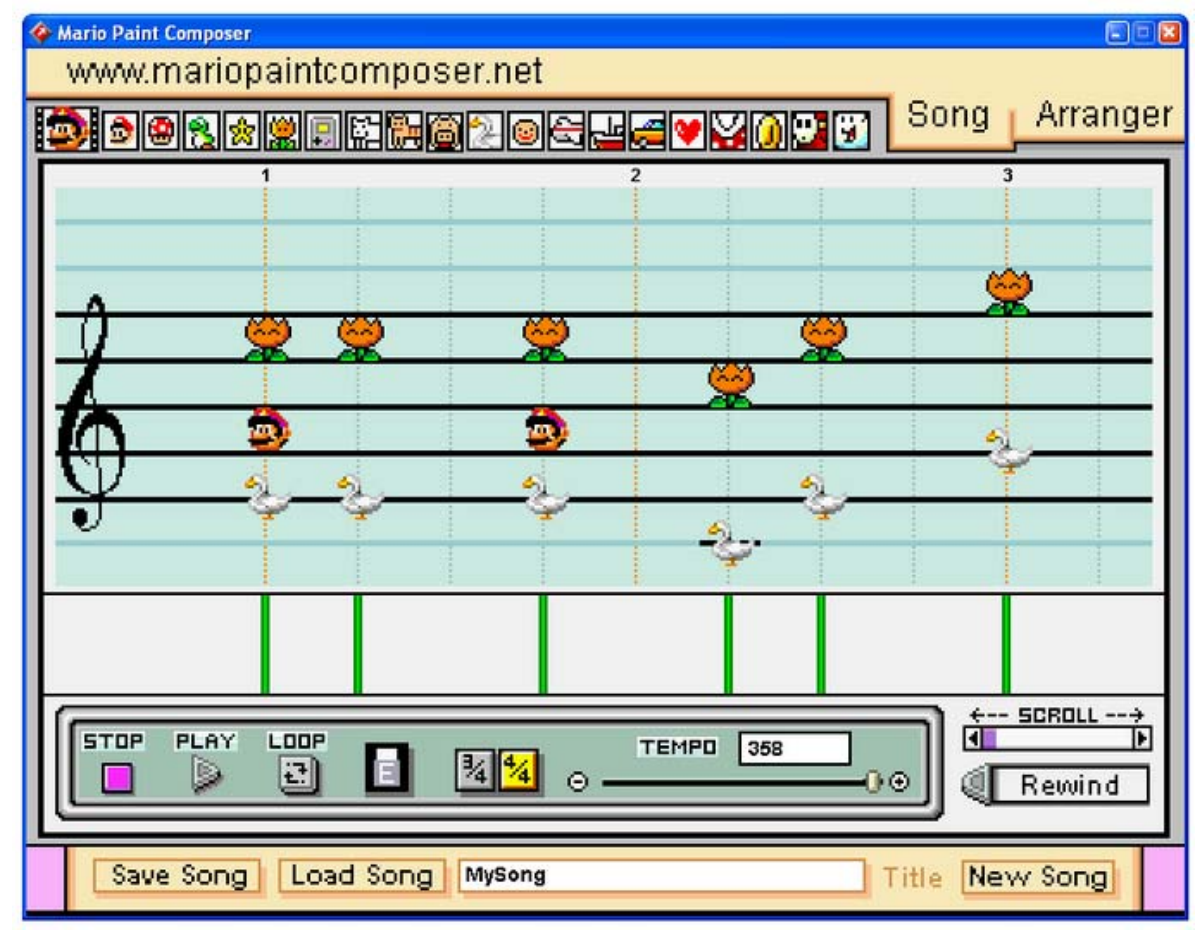

Figure 3. Interface from Mario Paint Composer v2.0.

(1) The pitch range is extended. The user may select pitches from $A 3^{12}$ to $C 6^{13}$.

(2) Accidentals are available, making accurate song transcription possible. Composers may compose in any key.

(3) Five simultaneous notes may sound at a time, up from three.

(4) The user may type in the desired beats per minute in a new text box or use the tempo slider bar.

(5) Any musical point with at least one note receives a volume bar located below the staff. The user may adjust the height of the bar. If there are two or more simultaneous sounds, they share the same volume bar.

(6) Volume can be used to create the musical effect of a decay or echo. This is achieved when a note at full volume is followed quickly by the same note at substantially less volume. The illusion of echo by this means is a prominent chiptune trait found in the music of NES and Famicom ${ }^{14}$ games.

(7) The user is not limited to the sound samples used in Mario Paint. The user can import a soundfont for different sounds.

(8) Songs may be saved as Mario Paint Composer files which can only be opened in Mario Paint Composer.

\footnotetext{
${ }^{12}$ A3 is the second ledger line below the treble staff.

${ }^{13}$ C6 is the second ledger line above the treble staff.

14 The Famicom is the Japanese counterpart to the NES.
} 
Multiple songs may be stringed together by clicking on the Arranger tab to form songs of longer length.

(9) The most noticeable omission is the animation of Mario running and jumping above the staff.

\section{Advanced Mario Sequencer (2009)}

Advanced Mario Sequencer is a reimplementation of the music mode of Mario Paint by Felix Krause. It addresses the musical and visual limitations of Mario Paint Composer (Krause, 2015). Figure 4 shows the interface of Advanced Mario Sequencer. The interface borrows from Mario Paint and Mario Paint Composer, while including additional features. The following minor changes from Mario Paint Composer are listed below.

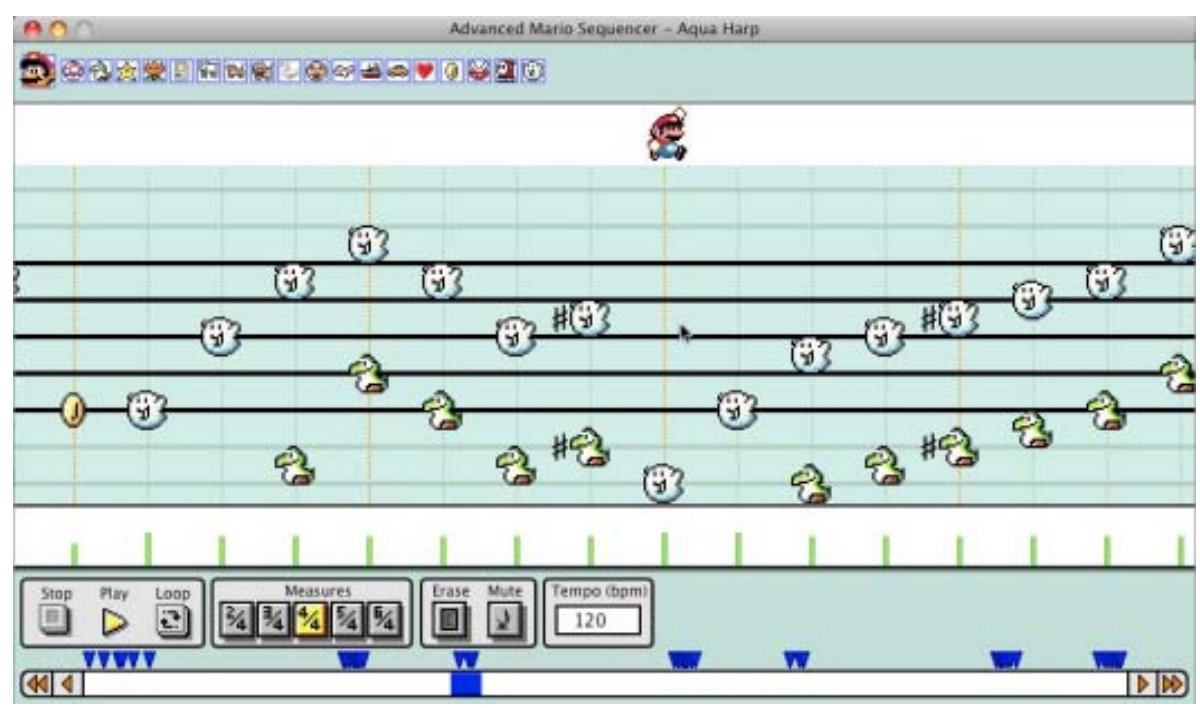

Figure 4. Interface from Advanced Mario Sequencer.

(1) A mute note is a note that cuts off the playback of a sound sample. Used primarily with sounds of long duration, the mute mode allows the user to designate where a sound should end.

(2) A bookmark is a shortcut to a specific part of a song, viewable above the scrollbar located at the bottom of the interface.

(3) A speedmark is similar to a bookmark, but has a change of tempo associated with it. The speed of the song changes during playback at the time location of the speedmark.

(4) Like Mario Paint, an animation of Mario running and jumping appears above the staff in playback, acting as a playback head.

WarioWare D.I.Y. (2010) ${ }^{15}$

WarioWare D.I.Y. is a game published and released by Nintendo in North America in March of 2010 for the Nintendo DS. It borrows heavily from Mario Paint as it focuses on user-generated content. Figure 5 shows the music tool that functions similarly to the music mode of Mario Paint. Both games share similar instruments and sound effects. WarioWare D.I.Y. replaces the five-lined staff with the piano-roll pitch representation more commonly found in DAWs. It uses the two screens and touch capability of the Nintendo DS in its interface. A user may sing into the built-in microphone for note input as well as for recording a new sound. One limitation is that only four instruments may be used for every two measures, not including drums.

${ }^{15}$ Also known as WarioWare: Do It Yourself. 


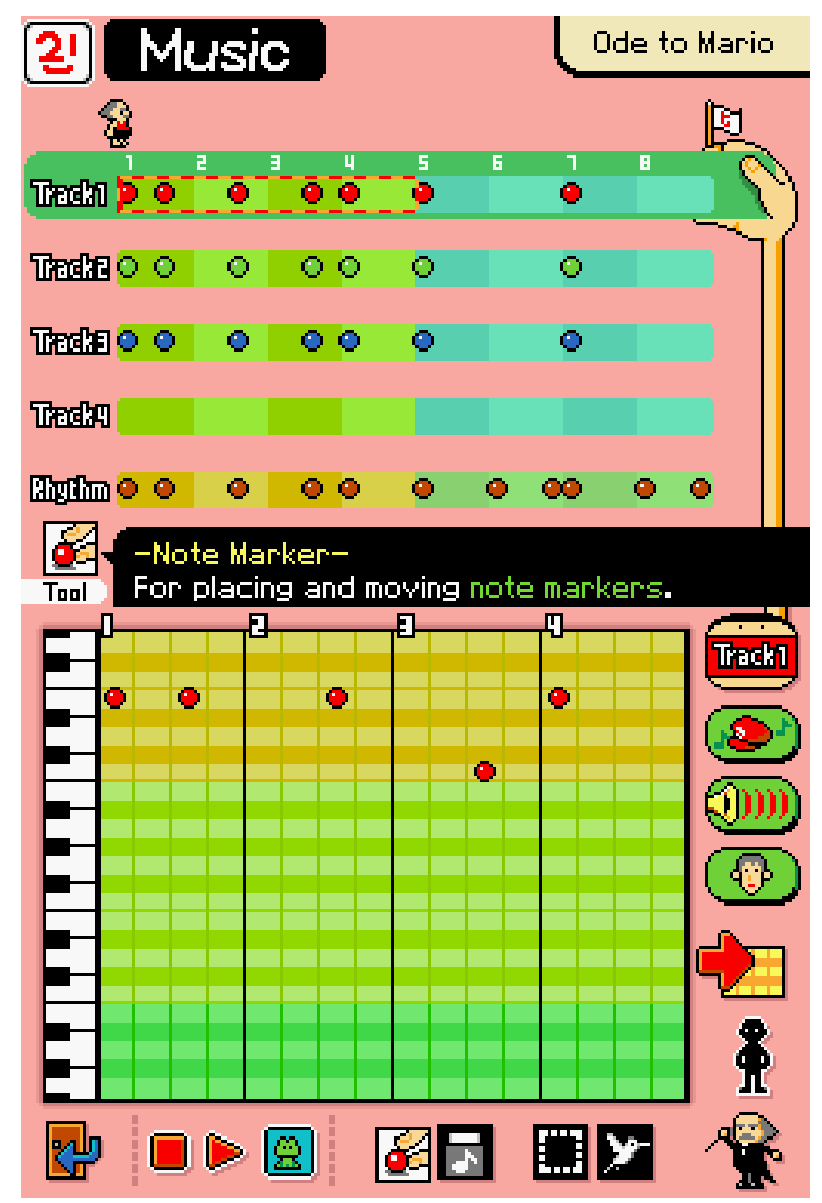

Figure 5. Interface from WarioWare D.I.Y.

\section{Mario Paint Inspired HTML5 Music Composer (2014) ${ }^{16}$}

The Mario Paint Inspired HTML5 Music Composer by Daniel X. Moore is the most accessible remake of the muisc mode to date, functional on most devices supporting HTML5. As seen in Figure 6, the design of the interface and icons reflects the editor as a browser application. As such, the program breaks away from the interface and features of other Mario Paint programs. The five-lined staff is replaced with the piano-roll pitch representation found in most DAWs. There are only five toned and five percussive sounds from Mario Paint. The time and pitch over which the mouse cursor is placed is displayed in the upper-right corner. The interface design assumes greater familiarity of a DAW presentation over the Mario Paint presentation.

What the program lacks in accessibility it makes up for in features. Some of the new features are the pitch range, simultaneous sounds, and sharing. The pitch range is the largest of all the programs at two octaves and an augmented fourth. ${ }^{17}$ There is no noticeable restriction as to how many sounds can reside on the same pitch as well as how many may sound at a time. Sharing songs with others on the web is possible now that each song has a unique URL when published. These features promote longevity of created content and encourage compositions with rich musical depth.

\footnotetext{
${ }_{17}^{16}$ Name is given by author. The URL is http://www.danielx.net/composer/.

${ }^{17}$ From pitches F3 to B5.
} 


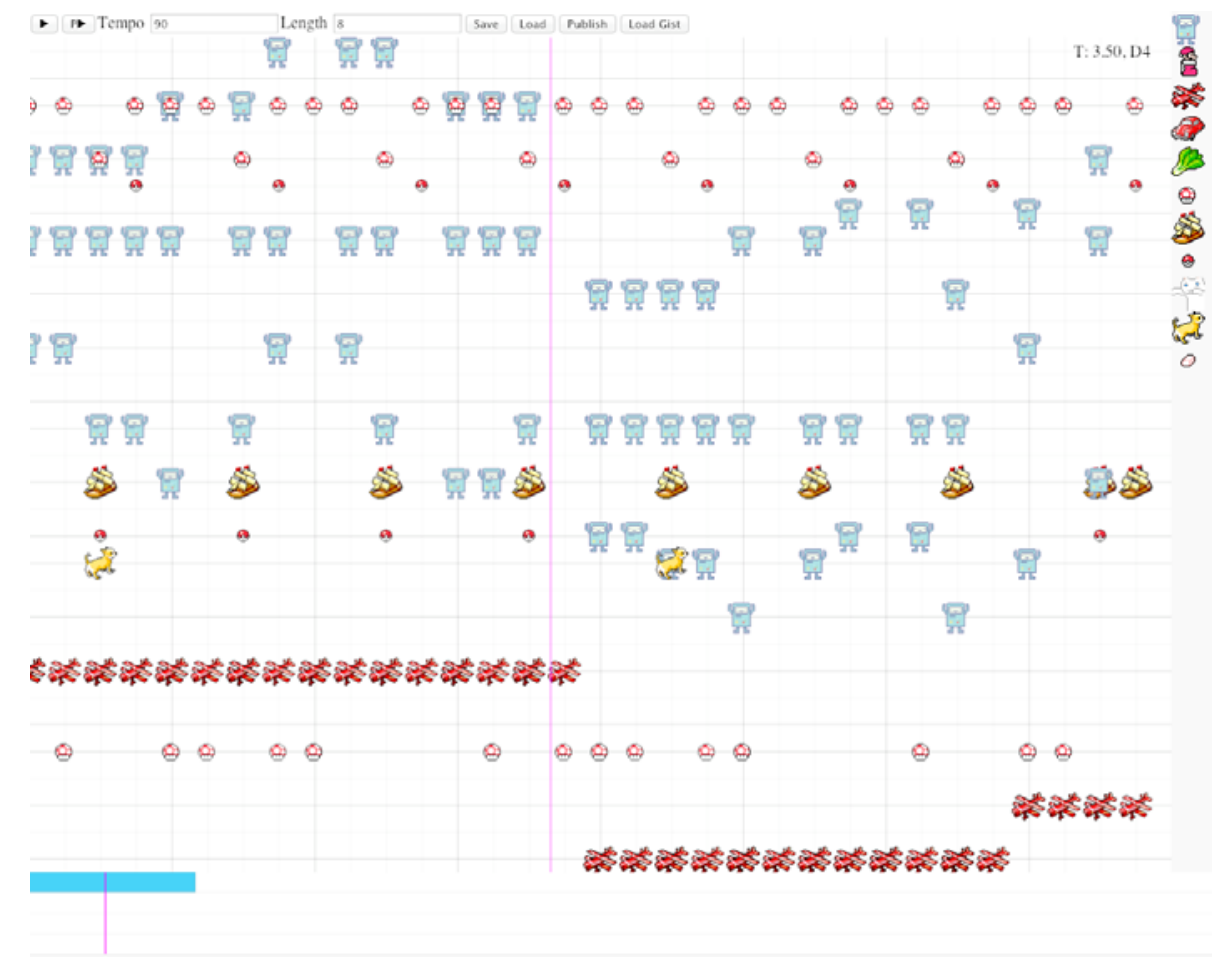

Figure 6. Interface from Mario Paint Inspired HTML5 Music Composer.

\section{Inspiration and Cultural Phenomenon}

Mario Paint is a blueprint of efficient interface design and ease of use. Although there has not been a direct sequel as of yet, the tools and game aspects of Mario Paint appear in other projects. Most of these projects recognize the ease of use of the music mode in addition to the playful aspects of music composition. Mario Paint was never promoted as a complete audio workstation but rather as a sandbox of musical possibility.

\section{Internet Video}

Musical works prepared with Mario Paint's music mode attract larger communities due to the sharing and social aspects of the Internet. A popular Internet video featuring music created in Mario Paint Composer is “Through the Fires and Flames—Dragonforce” Arranged by Levi Davis in 2008, the YouTube video currently has 6.4 million views (Davis, 2008). According to Davis, the arrangement, which plays for almost eight minutes, took close to fifteen hours to complete. Compositions and arrangements made in Mario Paint achieve Internet fame through the popularity of the original songs, if any, and the quality of the musical arrangements.

\section{Wii Music (2008)}

Wii Music is a game for the Nintendo Wii that, like Mario Paint, condenses the musical experience into an interactive and appealing game. Wii Music takes inspiration from Mario Paint; however, "the problem with Mario Paint was that, while fun, it required the player to actually compose a song note by note, then simply played that back in a purely flat manner (no dynamics, etc.)" (England, 2008). Wii Music sought to remove the music notation from the game, promoting musical development through listening rather than seeing. Like Mario Paint, Wii Music is a game that “doesn’t present you with a defined objective but does give you a great degree of 
freedom to go around and allows you to define your own goal within that” (Totilo, 2008). Mario Paint exhibits the same freedom of choice from which a user can create compelling music. This point makes it a successful and accessible music-composition environment.

\section{Super Mario Maker (2015)}

The music-editing features of Mario Paint would fit well within a game-design or level-editing program. Super Mario Maker, released in North America on September 11, 2015, is a game creator application by Nintendo for the Wii U designed for level creation in the visual styles of 2D Super Mario games. Despite including a streamlined interface for level creation of various Super Mario iterations, it does not ship with a music editor. Nevertheless, Nintendo has implemented some tools and tips to encourage customization of sound effects and music. The editing interface is inspired from Mario Paint as evidenced by the frog and dog icons which have the features of sound effects and undo, respectively. In its retail release, the editor is capable of custom music as a gameplay element. The note block typically used to propel Mario upward in Super Mario games, when shaken in the editor, becomes a music block. The height of the music block within the level determines the pitch it plays when any object hits it. Through advanced level design and musical skills, one can arrange music blocks to play a song as the player advances, demonstrated by Nintendo in one of their overview videos prior to the game's release (Nintendo, 2015). Perhaps in the future, Nintendo may offer additional musical control like that in Mario Paint so that the player becomes the composer and ultimately the creator of a full multi-sensory interactive journey.

\section{In the Classroom}

The study of Mario Paint and its successors shows an evolution of musical needs and limitations from a video-game perspective. This is the focus of "Mario Paint DeCal”, a university course offered through the DeCal program at the University of California, Berkeley. Last offered in the spring of 2014, the course provides "a solid foundation on the techniques of using Mario Paint Composer and its variants, along with providing a quick overview of how the program and its users changed over its years of service (2007-present)" (Mario Paint DeCal, 2014). As a student-driven course, it acknowledges that despite its lack of full audio features, Mario Paint and its successors are accessible and manageable in a classroom environment.

\section{Conclusion}

As an environment for musical composition, the music mode of Nintendo's Mario Paint is accessible to composers of all skill levels and experience. It is especially valuable to those composers who wish to work within the limitations of the Super NES sound chip. Upon mastering Mario Paint, there are modern offerings that maintain the feel with additional musical and sharing options. While modern DAWs and music notation software include numerous features and settings that present a steep learning curve, Mario Paint is very much approachable as a learning tool for music theory and composition for all ages.

\section{References}

Davis, L. (2008). Mario Paint-Through the Fire and Flames-Dragonforce [Video file]. Retrieved July 26, 2015 from https://www.youtube.com/watch?v=hil1F2T19GY

eataninja. (2011). The Official Mario Paint Composer FAQ. Retrieved from http://mariopaintcomposer.proboards.com/thread/5427/official-mario-paint-composer-faq 


\section{AN ACCESSIBLE ENVIRONMENT OF MUSICAL CREATIVITY AND SOUND EXPLORATION}

England, K. (2008). Miyamoto defends wii music. Retrieved July 26, 2015 from http://www.geek.com/games/miyamoto-defends-wii-music-636292/

Hackett, L. (2013). Mario Paint 16-page advanced features guide in Nintendo Power Vol. 44. Retrieved July 26, 2015 from http://www.superluigibros.com/mariopaint-guide-nintendo-power-44

Hackett, L. (2013). Mario Paint in Nintendo Power Vol. 39. Retrieved July 26, 2015 from http://www.superluigibros.com/mario-paint-nintendo-power-39

Japancommercials4U2. (2009). Mario Paint JPN commercial [Video file]. Retrieved July 26, 2015 from https://www.youtube.com/watch?v=1V0KJWNquu0

Krause, F. (2015). Manual of the Advanced Mario sequencer. Retrieved July 26, 2015 from http://flyx.org/projects/ams/manual/

Mario Paint. (n.d.). Retrieved July 26, 2015 from http://www.mariowiki.com/Mario_Paint

Mario Paint DeCal. (2014). Retrieved July 26, 2015 from http://www.decal.org/2977

Mario Paint: Nintendo player's guide. (n.d.). Retrieved July 26, 2015 from http://annarchive.com/files/Mario\%20Paint\%20-\%20SNES\%20-\%20Nintendo.pdf

Nintendo. (2015). Wii U-Let's watch! Super Mario Maker overview! [Video file]. Retrieved August 12, 2015 from https://www.youtube.com/watch?v=_9W_y8IlNro

Totilo, S. (2008). One-On-One with Shigeru Miyamoto: From “wii music” to Bowser to...MotionPlus? Retrieved July 26, 2015 from http://multiplayerblog.mtv.com/2008/10/27/one-on-one-with-shigeru-miyamoto/

Trammell, A. (2010, October 6). Genre in the age of convergence: Mario Paint Composer. Retrieved July 26, 2015 from http://soundstudiesblog.com/2010/10/06/genre-in-the-age-of-convergence-mario-paint-composer/ 